Mention is also made of the injection of the intervertebral ganglia with novocaine, which is found to be a very useful treatment. It is a pity perhaps that a simple remedy like oil of cloves is not mentioned in the treatment of neuralgia of dental origin but, apart from one or two very minor omissions of this sort, the book is complete.

The therapeutics of analgesia include the nursing of pain, baths and packs by Dr. Mathew Ray and, lastly, there is a complete list of analgesic drugs with instructions as to dosage.

This book was definitely original in its conception and most doctors, certainly the busy ones who have not time to look up original papers or read long textbooks, will find that it fully meets all their needs.

\section{THE PATHOLOGY OF INTERNAL DISEASES.}

By William Boyd. 3rd Edition. Pp.874. Henry Kimpton. London. 1940. Price 45s. 0d.

The author has succeeded in giving us an illustrated text-book of internal medicine in which the mechanism of disease is described. After each discussion of subjects of major importance there is a most useful commentary on the relation of symptoms to lesions. The author not only deals with morbid anatomy but discusses his subject from the view point of pathological physiology. The diseases included in the text are those which are found in the medical wards of a teaching hospital and included in a course of study for a higher examination in medicine. Omissions are infectious fevers, tropical diseases and conditions having no known morbid anatomical basis.

This volume forms a useful companion to Boyd's book on Surgical Pathology and there is necessarily a certain amount of overlapping present in these two books. In this third edition new material has been added and a number of sections have been rewritten.

With regard to certain details in the subject matter we are pleased to note that in the section on cancer of the stomach the author states that the only symptoms worth discussing are the early symptoms; we feel that the early symptoms should have been described in much greater detail. The more recent conceptions on jaundice are dealt with clearly, including the work on Vitamin K - the anti-hæmorrhagic vitamin. Amongst other new matter which has been incorporated is: Fiedler's myocarditis, hypertensive heart disease, internal coronary hæmorrhage, Lederer's acute hæmolytic anæmia, the reticuloses, extrarenal uræmia, the relation of pyelonephritis to arterial hypertension and the prevention of silicosis.

Considerable care has been expended on the illustrations, including photo-micrographs giving the magnification thus conveying a true idea of the dimensions of the structures depicted. The. book is well produced and is to be recommended to all who desife a sound knowledge of pathology from the physician's point of view.

\section{MODERN TREATMENT IN GENERAL PRACTICE. Year Book, I940.}

By Cecil P. G. Wakeley. Baillière, Tindall \& Cox. 1940. Price 12s. 6d.

This is an excellent year book, presenting in a clear and concise form the newest methods of diagnosis and treatment. The present volume upholds the high standard of its predecessors. In the presence of so many good and helpful articles it is difficult for the reviewer to select some for special mention. Lord Horder deals with the treatment of hyperpiesia and symptomatic hypertension and calls attention to the fact that many of these patients require no special treatment, least of all by drugs, and they should be given general guidance preceded by a clear and reassuring explanation of the position. Sir Robert Kelly reviews the problem of jejunal ulcer and gastro-colic fistula. He considers that fixation of the stroma and failure to allow duodenal secretions full play over the stroma as in the Roux operation are the most important technical considerations in the etiology. In the treatment of cancer of the rectum Sir C. Gordon-Watson advocates Hartmann's operation for growths low down in the pelvic colon which are too low for resection-anastomosis; we are glad to note the restraint with which the author deals with conservative methods in this disease. Sir James Walton in discussing the treatment of acute cholecystitis advises early operation. The treatment of burns under war conditions is dealt with in a helpful way by Mitchiner. Gordon-Taylor deals authoritatively with the controversial subject of the bleeding peptic ulcer and states that the greatest judgement and caution must be exercised before pressing surgical intervention and that surgery, if it be required during active ulcer-hæmorrhage, should be utilised in the early hours of the bleeding. Medical conditions are considered in many excellent articles and stress is laid on the recent therapeutic developments. Thus Morlock writes on pneumonia; Wilfred Payne on diabetes in children; Newman on cirrhosis of the liver; Whitby on septicæmia; Worster-Drought on neurosyphilis. The treatment of gynæcological conditions is given a place and Vartan contributes an article on menstrual disorders and Green-Armytage on sterility.

We congratulate Wakeley as editor of the volume in providing the profession with a most helpful book and we recommend it to all who desire to keep abreast with recent developments in treatment.

\section{DISEASES OF THE NERVOUS SYSTEM.}

By W. Russell Brain. 2nd Edition. Pp. 950. 76 illustrations. Oxford University Press. 1940. Price 30s. Od.

The first edition of this book appeared in 1933 and it rapidly became a popular exposition of neurology. In preparing his second edition the author has wisely avoided undue enlargement of 